\title{
ESTEREÓTIPOS EM SALA DE AULA
}

\author{
STEREOTYPES IN THE CLASSROOM
}

\author{
Maria Eduarda Hilarino Drumond ${ }^{1}$ \\ Maria Cândida Trindade Costa de Seabra ${ }^{2}$
}

\section{APRESENTAÇÃO}

A intenção de se discutir estereótipos em sala de aula, tema que estruturará o presente artigo, surgiu durante a realização do meu estágio obrigatório - requisito para a aprovação na disciplina “Análise da Prática e Estágio de Português I" - no ano de 2017. Ao conviver com os alunos do $6^{\circ}$ ao $8^{\circ}$ anos, pude notar que, por influência de uma sociedade acostumada a generalizar pessoas ou grupos por meio de seus comportamentos ou características afins - os alunos da escola estadual "Professora Conceição Hilário" não estavam isentos da influência da construção de pressupostos. Por esse motivo, juntamente com a aprovação, ajuda e incentivo de minha professora orientadora, decidi trabalhar esse tema com os alunos do $8^{\circ}$ ano do Ensino Fundamental II.

O presente artigo, então, tem por objetivo relatar a minha experiência enquanto professora estagiária e como foi a recepção dos alunos do $8^{\circ}$ ano em relação ao tema a eles proposto tanto como forma de conhecimento quanto como forma de avaliação, que se realizou por meio de um artigo de opinião.

\section{CARACTERIZAÇÃo DA ESCOLA E DE SUAS PRÁTICAS DIDÁTICO- PEDAGÓGICÁS}

Antes de iniciar esta seção, gostaria de ressaltar, aqui, que todas as informações aqui descritas e as afirmações feitas foram baseadas unicamente em minhas opiniões e percepções pessoais e que não são fundamentadas empiricamente.

A escola que eu escolhi para estagiar fica na cidade de Contagem/MG. O bairro onde ela se localiza é tranquilo, mas é cercado por bairros periféricos, de onde provém a maior parte de seus alunos. Contudo, em relação ao ensino, a comunidade, em geral, qualifica a escola como sendo uma das melhores localizadas nesse bairro.

Fisicamente, a escola ocupa exatamente um quarteirão e é cercada por paredes de cimento sem pintura. O portão da entrada é bem velho e está um pouco enferrujado. Além disso, as janelas de todas as salas possuem grades, o que, o que me minha opinião, mais passa a sensação de prisão do que de escola. Já os aposentos da escola foram construídos com tijolinhos, mas bem estruturados. A escola possui dois andares e, ao todo, é composta por dez salas de aula ocupadas por aproximadamente 35 alunos em cada turma. Há quadros brancos e carteiras novas bem conservadas nas salas, dois banheiros, um masculino e um feminino, uma biblioteca muito escassa, em que quase não se encontra livros literários na quantidade ideal para o usufruto de todos os alunos, uma sala de informática com computadores novos onde também se encontra projetor, a sala dos professores, a secretaria e a sala do diretor.

Em relação aos contextos didático-pedagógicos, pude perceber, a partir de anotações que fiz enquanto observava os professores e o modo como eles planejavam e davam as suas aulas, que todo o grupo docente se preocupa muito com a educação de seus alunos. O diretor da escola sempre está presente, ajudando e auxiliando professores e alunos durante o percurso escolar. Muitos professores, como os de história, ciências e geografia, gostam de dar aulas na sala de

\footnotetext{
${ }^{1}$ Universidade Federal de Minas Gerais, Graduada em Letras. Contato: duda.mia@hotmail.com.

${ }^{2}$ Universidade Federal de Minas Gerais, Professora Doutora. Contato: candidaseabra@gmail.com.
} 
informática, onde podem utilizar o projetor e dar uma aula expositiva aos seus alunos, fugindo um pouco do contexto de sala de aula, o que deixavam os alunos muito satisfeitos, uma vez que, por meio dessas aulas expositivas, eles conseguiam mergulhar, de fato, na matéria escolar que estavam estudando naquele presente momento e não apenas imaginar, já que os professores sempre traziam vídeos ou experiências que baseavam o conteúdo educacional que estavam transmitindo.

Já a professora de língua portuguesa que eu acompanhei durante o estágio gostava de fazer aulas ao ar livre, que consistiam em levar os alunos aos canteiros abertos da escola, dispô-los em círculos e discutir os tópicos propostos por ela para aquela aula em específico, tratando-se, mais comumente, de aulas voltadas para a literatura do que para a gramática em si, pois justificava que os alunos precisavam de experiências novas ao invés de só ficarem presos a uma sala de aula. Ela se preocupava bastante com o desenvolvimento dos alunos e, por isso, gostava de ajudá-los a desenvolver a leitura, interpretação e produção de textos, apesar de a leitura dos alunos, em geral, ser melhor do que a escrita. Afirmo, aqui, que tal conclusão baseou-se na observação das aulas de leitura e na avaliação dos textos produzidos pelos alunos cuja correção estava sob a minha responsabilidade.

A professora planejava suas aulas com cuidado, interagia bastante com os alunos e avaliava a participação deles durante a aula. Mas o que eu mais gostei de sua didática é que ela sabia diferenciar o seu contexto do contexto de seus alunos, ou seja, sabia que cada aluno ali presente possuía experiências e conhecimentos diferentes dos dela e, assim, tendia a adequar suas aulas partindo do conhecimento prévio que os alunos possuíam sobre a matéria que ela iria lhes ensinar como, por exemplo, ao ensiná-los sobre linguagem formal e informal e em qual contexto conversacional cada tipo de linguagem deveria ser usada, ela utilizava o cotidiano dos alunos como referência. Assim, ela empregava expressões como "colê irmão, o que cê vai fazer hoje?", algo que estaria mais presente na linguagem de seus alunos, contrastando com a forma exigida pela gramática: "Olá, meu amigo! O que você fará hoje?”.

A professora também corrigia todas as atividades dadas em sala de aula juntamente com seus alunos, levando-os a interagir com ela durante a correção. Ela também se preocupava em avaliálos de várias formas, não se detendo apenas na aplicação de provas, mas analisando-os, também, por meio de atividades adjacentes, como o dever de casa, trabalhos de língua portuguesa, ditados, entre outros. Mas, a professora optava por trabalhar gramática com os alunos por meio de exercícios durante suas aulas e valorizava mais a interpretação e produção textual em suas avaliações.

A professora de língua portuguesa também era a responsável pelo projeto de leitura realizado pela escola. Ela dizia que primeiro gostava de praticar com os alunos a leitura e interpretação de textos em todas as suas aulas para aperfeiçoar o desenvolvimento dos deles nesse campo, antes que pudessem escolher um livro para ler. Todavia, durante a realização do projeto, a professora dizia que os deixava livres para escolher o livro com o qual eles mais se identificam para que pudessem lê-lo por prazer e não por obrigação.

Entretanto, vale ressaltar que os projetos pedagógicos realizados na escola durante o ano eram bem poucos e aconteciam mais durante datas comemorativas como a festa junina onde os alunos ensaiavam músicas para fazer uma apresentação para a comunidade. Também havia, na escola, os projetos de leitura, como mencionado anteriormente, mas como aconteciam, normalmente, no último bimestre do ano, a biblioteca ficava praticamente, todos os dias, vazia.

Além disso, pude notar, através de minhas impressões gerais, que a figura do professor é muito desvalorizada pelos alunos, pois eles, de maneira geral, não respeitam os docentes como uma figura de autoridade.

A maioria dos alunos fazem as atividades para conseguirem nota, mas não possuem intuito de aprender de fato o que lhes está sendo ensinado. Digo isso, pois, muitas vezes, ao perguntarlhes sobre quais profissões gostariam de seguir ou se seguiriam carreira acadêmica, a maioria dos 
alunos respondia ou que estavam ali porque eram obrigados pelos pais ${ }^{3}$ ou porque queriam ter o diploma de Ensino Médio da forma mais fácil possível, sempre dizendo: "Professora, você sabe que a escola não pode nos reprovar...". Os professores, também, sempre precisavam negociar com os alunos para que houvesse silêncio na sala enquanto faziam a explicação da matéria ou enquanto realizavam a correção dos exercícios.

Mas, é claro que, vale dizer que para se obter uma melhor avaliação dessas afirmações, estudos destinados a esse fim deveriam ser colocados em prática para uma melhor obtenção de dados empíricos.

As salas de aula são mapeadas, ou seja, cada aluno possui um assento definido na sala. Como justificativa dos educadores, essa iniciativa foi a única que encontraram para amenizar a bagunça e a conversação dos estudantes.

Por fim, a maioria dos alunos não se mostra de fato interessados em aprender, pois não copiam matéria e não fazem as atividades propostas pelo docente, chegando ao ponto de o professor ter que chamar os pais desses alunos para discorrer sobre a falta de irresponsabilidade de seus filhos.

\section{O ESTEREÓTIPO EM SALA DE AULA}

Feldhaus e Miziescki (2016, p. 5) dizem que os estereótipos

Podem ser considerados como generalizações originadas de um coletivo e de uma forma individual, que são apontadas como características comportamentais (cultura, aparência, gênero, classe econômica, e entre outros) de outras pessoas dentro de um círculo social. Tais perspectivas podem ser compreendidas também enquanto rotulação seja de cunho pejorativo, ou não, como algo prejulgado. Tais representações possuem caráter dogmático em determinadas circunstâncias, que ocasionam um processo lento de desconstrução. Ao surgir algo que é incomum aos olhos de um grupo social, tal particularidade terá maior vulnerabilidade perante o que é ditado como algo habitual por este.

Ainda segundo Feldhaus e Miziescki (2016, p. 6),

Determinados estereótipos são consequências de veículos midiáticos (televisão, internet, jornais, revistas, filmes, entre outros), o que os tornam popularmente fortes por chegarem de forma até manipuladora em cada residência. Os padrões (beleza, moda, comportamento e etc.), são ditados nas telenovelas, nos seriados e filmes hollywoodianos (que incluem animações), e entre outros, frutos muitas vezes, de uma concorrência de ideias capitalistas que a cada dia buscam abranger um maior número de pessoas, para torná-las consumidoras de seus produtos... Estes meios de comunicação, durante excessivas vezes, nos impõem uma postura alienada de inúmeros modos, dispondo de uma tentativa de convencimento do que julgam necessário para seus interesses.

Feldhaus e Miziescki (2016, p. 6) ainda declaram que "Os estereótipos fazem parte da realidade de muitas escolas, de forma enraizada, não somente nas paredes das salas de aula, mas de forma alicerçada na cabeça das pessoas (pais, professores, direção e sociedade em geral)".

Pereira (2002) indica que ao interagirmos com uma pessoa, não damos importância somente ao que ouvimos ou vemos, mas, de igual forma, levamos em consideração o conhecimento sobre grupo social do qual pertencemos e sobre o grupo social do qual a pessoa que interagimos faz parte (PEREIRA, 2002). Nesse sentido, torna-se necessário ao professor, em algum momento de seu ano letivo, discutir a questão do estereótipo em sala de aula, já que - como dito anteriormente -

\footnotetext{
3 A maioria dos pais dos alunos que frequentam a escola tem renda proveniente do programa "Bolsa Família". Assim, para que continuassem recebendo a quantia designada, muitos pais tinham que manter os seus filhos na escola.
} 
vivemos em uma sociedade acostumada a criar rótulos, e é conveniente mostrar aos alunos a consciência de que, na maior parte das vezes, o estereótipo não define de fato uma pessoa ou um grupo (HAMAUE, 2008).

Segundo Jakubaszko (2015, p. 3),

Para saber organizar a vida e o mundo, o ponto de partida é a observação, descrição e compreensão desse mundo. Para observar, descrever e compreender é preciso ter conceitos e categorias: utilizar a capacidade de generalizar, de ver num amontoado de coisas, pessoas e acontecimentos um sentido, e de buscá-lo por meio de semelhanças e contrastes, de separar e reunir todos esses elementos em conjuntos, em universos.

A autora continua,

E por que fazemos isso? Para que servem os estereótipos afinal? De um lado, funcionam como um mecanismo de reconhecimento fácil que simplifica nossa ação cotidiana; de outro, podem reforçar preconceitos e ações discriminatórias, fomentando relações assimétricas de poder em nossa sociedade. Isso porque "os estereótipos estão, portanto, altamente carregados com os sentimentos que estão presos a eles. São as fortalezas de nossa tradição, e atrás de nossas defesas podemos continuar assentir-nos seguros na posição que ocupamos. (JAKUBASZKO, 2015, p.3)

Levando-se, então, em consideração o que foi discutido acima sobre os estereótipos e o comportamento apresentado pelos alunos em relação a mim, quando de fato comecei a estagiar, decidi discutir esse assunto tão relevante com os alunos que seriam, por bastante tempo, meus companheiros de trabalho.

Ao discutir esse tema, antes de expô-lo aos alunos, com a professora que me orientou no estágio, deparei- me com o fato de que ela havia entrado há pouco tempo em seu cargo por designação, pois a professora titular estava de licença maternidade. Ela me contou que ao tomar posse de seu cargo, inicialmente, sentiu um pouco de rejeição por parte dos alunos, mesmo que eles ainda não a tivessem conhecido de verdade. Disse-me que para conquistar o carinho e a confiança deles foi um pouco difícil, já que eles haviam criado estereótipos tanto em relação a professores novatos quanto em relação a professores de Língua Portuguesa em si.

Percebi, então, que a rejeição com a qual me deparei por parte dos alunos, nas primeiras vezes em que fui assistir às aulas, não estava relacionada diretamente com a minha pessoa em si, uma vez que eles mal me conheciam, mas com a imagem de professor novato e de professor de Língua Portuguesa que eles haviam criado, durante a sua vida escolar.

Descobri em conversas com os alunos, que a professora titular de língua portuguesa era uma professora severa e que não dava quase nenhuma liberdade para que eles pudessem se expressar ou até mesmo soltar a criatividade. Eles me contaram que ela seguia estritamente o livro didático e não possibilitava uma abertura para atividades diferentes que não estivessem ligadas ao livro.

Ainda conversando com eles, notei que eles gostavam muito da professora substituta, pois ela trabalhava com eles mais do que somente o livro didático, criando projetos diferentes, como o projeto de leitura em que ela permitia que os alunos escolhessem o livro com o qual mais se identificassem para que, depois, pudessem realizar um trabalho em que os estudantes deveriam falar sobre o livro que escolheram e como esse projeto de leitura os ajudou a melhorar a maneira como liam e como escreviam.

Os alunos me falaram que, para eles, foi uma surpresa conhecer uma professora que fosse diferente da anterior, pois eles já haviam criado em suas mentes a imagem de que todos os professores de língua portuguesa eram rígidos. Porém, ao me conhecerem - apesar da experiência boa que tiverem em relação à professora substituta - ficaram meio receosos, pois pensaram que eu era brava e "chata", como eles mesmos me relataram depois.

Assim, devido ao fato de os alunos sempre criaram rótulos sem antes conhecerem de fato as 
pessoas com as quais estavam interagindo, decidi trabalhar esse assunto tão polêmico que circunda a cultura de nossa sociedade com o $8^{\circ}$ ano, a turma mais veterana do turno da tarde (horário em que eu estagiava).

Entretanto, como iria pedir aos alunos que, ao final da discussão sobre o assunto, fizessem um artigo de opinião, me certifiquei, primeiramente, de que esse gênero textual já tivesse sido abordado e trabalhado em sala de aula. Dessa maneira, conversei com a professora e ela havia dito que os alunos do $8^{\circ}$ ano já haviam estudado este tipo de gênero textual.

Sendo assim, para a realização do trabalho, pedi que a professora me cedesse uma aula para que eu pudesse abordar esse tema com os alunos e ela me concedeu. Inicialmente, abordei com os alunos o tema com o qual iríamos trabalhar durante a aula que eu iria dirigir. Eles ficaram entusiasmados com o assunto, mas fazendo um levantamento antes de iniciar o projeto, notei que eles não conheciam muito sobre o que iríamos discutir.

Por isso, para que eles se situassem sobre o assunto que iríamos comentar, pensei em levar um vídeo que discutisse esse assunto, mas não de forma rebuscada e, sim, que pudesse dialogar com os alunos através da linguagem mais coloquial (linguagem mais presente no contexto deles).

Encontrei, então, um vídeo de aproximadamente 5 minutos no site - muito utilizado pelos estudantes em geral - do Youtube (caracterizado por ser uma plataforma de distribuição digital de vídeos). O vídeo, intitulado Estereótipos nossos de cada dia, do Youtuber, Kartoffel Salat, fala sobre como o povo brasileiro, de forma geral, postula os povos de outras nações e como os povos de outras nações postulam os brasileiros.

A intenção que nos levou a discorrer sobre esse assunto com os alunos era fazê-los refletir a não fazerem julgamento, pelo conhecimento prévio que possuem, de uma pessoa ou um grupo social quando os conhecessem, mas que de fato procurassem saber como aquele grupo ou aquela pessoa é realmente.

Ao terminarem de assistir ao vídeo, pude notar que muitos alunos se identificaram com as declarações feitas pelo Youtuber. Assim, para fazer com que os alunos expusessem suas opiniões, levantei uma discussão explicando para eles o significado da palavra estereótipo, então pedi que me dissessem o que pensaram sobre o vídeo e quais eram as opiniões deles sobre o assunto. Muitos deles me disseram que, ao olharem para mim a primeira vez, já me tomaram por pessoa "chata" pois, pelo o que eles diziam, eu tinha uma "cara" de brava e a medida que foram me conhecendo, perceberam que nada é o que parece ser e que devemos tirar conclusões quando, de fato, conhecemos aquilo que estamos avaliando.

Ao iniciar a discussão, percebi que os alunos haviam entendido de fato o que era estereótipo, pois souberam fundamentar o seu ponto de vista sobre o assunto, por meio de argumentos embasados de exemplos de situações que eles já sofreram, por serem vítimas de estereótipos, ou que eles já praticaram, por rotular alguém sem conhecer.

Após a discussão, pedi que eles fizessem um artigo de opinião em que colocariam, por escrito, a opinião sobre o assunto em geral, mas afunilando o assunto, ou seja, não pretendia que eles discutissem sobre como o brasileiro é visto por outras nações ou como as outras nações enxergavam os brasileiros. O meu principal objetivo era fazer com que os alunos escrevessem argumentos que pudessem defender expondo as experiências que eles mesmos vivenciaram.

\section{AVALIAÇÃO DOS RESULTADOS}

O resultado final foi o esperado, uma vez que eles conseguiram expor e fundamentar em seus artigos o ponto de vista que defendiam e as experiências, relacionadas ao estereótipo, pelas quais passaram. Resolvi não apresentar nenhuma das redações neste presente trabalho, pois não queria expor nenhum dos alunos, mesmo que os seus nomes fossem omitidos. Mas vale ressaltar que a correção das redações foi feita pela professora e ela mesma as avaliou.

Segundo Ilze Arduini de Araújo Oliveira e Eliete Antônia da Silva ([200?], p. 3-4), no artigo intitulado Estigmatizados: de que forma o professor aborda o preconceito no âmbito escolar, 
A escola deveria ser um lugar onde esses grupos (os que sofrem exclusão social, grifo nosso) se sentissem amparados, seguros e respeitados, um lugar de aprendizagem, livres de estereótipos e discriminação. Mas, apesar de termos muitos educadores e profissionais ligados à educação que trabalham visando essa utopia, sabemos que essa ainda é uma tarefa muito difícil de ser alcançada nas escolas brasileiras, mas não impossível.

Dessa forma, para evitar que haja problemas de exclusão dentro da sala de aula entre os próprios alunos, é importante que o professor conscientize os seus alunos das consequências de se rotular pessoas que mal conhecemos. Conforme Socha (2004, p. 19),

A escola que se necessita é aquela que conquista a participação pela realização da justiça social, é aquela que acolhe todas as crianças, excelentes ou não; crianças que depositem nela a esperança de um futuro melhor, originárias de famílias pobres, e por isso esperam por essa chance há muitos e muitos anos. Mas também não é só isso: a escola enquanto ambiente propício e acolhedor é aquela que recebe todos os "rebeldes" sem indiferença ou hostilidade, é aquela que por extensão, recebe tudo o que pode estar associado a elas: violência, pobreza, desorganização familiar, desemprego, alcoolismo, roubo, drogas, prostituição, desinteresse e dificuldades.

Segundo Bourdieu (1989, p. 49), “a força do pré-construído está em que, achando-se inscrito ao mesmo tempo nas coisas e nos cérebros, ele se apresenta com as aparências da evidência, que passa despercebida porque é perfeitamente natural. A ruptura é, com efeito, uma conversão do olhar".

Dessa forma, é de grande importância que o professor debata com os alunos sobre temas polêmicos e pouco discutidos em sala de aula, incentivando-os a pesquisar ou a se informar melhor sobre um determinado assunto ou sobre uma determinada pessoa, para que o aluno possa aprender a desconstruir aos poucos as visões errôneas que tivera sobre determinados conceitos.

Esse processo de desconstrução é de fundamental estima, pois apesar de sabermos que a situação não será totalmente erradicada, pelo menos saberemos que os nossos alunos estão cientes dos problemas e das consequências que podemos causar ao avaliarmos situações de maneira prévia sem ter o devido conhecimento sobre o que estamos julgando.

Jakubaszko $(2015$, p.7) explica que

A vida cotidiana é feita de ação e percepção. Na rotina alucinante não há tempo para reflexão científica que sirva de fundamento às nossas ações cotidianas. Nosso espaço de atuação é um pequeno mundo, finito, que cabe num reduzido círculo de experiências. Como já afirmamos, do mundo conhecemos apenas uma superfície: não há tempo para conhecimento íntimo e profundo das coisas, acontecimentos e experiências. Antes de tudo, é a necessidade pragmática que se impõe e faz prevalecer uma lógica funcionalista, e imediatista, para motivar nossas ações... Assim, a ultrageneralização é uma operação característica da vida cotidiana: as nossas decisões, comportamentos e atitudes baseiam-se em avaliações probabilísticas. Toda ultrageneralização muda com o tempo e as necessidades cotidianas; é sempre um juízo provisório ou uma regra provisória de comportamento. O cotidiano se alimenta das relações sociais e tendemos a confiar no discurso e na visão daqueles que nos sentimos próximos, familiares: o grupo a que nos sentimos pertencentes. Fazendo assim, simplificamos a vida cotidiana; tornamo-la mais segura, menos hostil.

Por isso, também é função do professor informar e discutir sobre assuntos como estereótipos em sala de aula. É de extrema seriedade que ele instrua seus alunos a como ficarem informados sobre um determinado assunto ou como devem conhecer alguém primeiro antes que possam simplesmente formular suas próprias conclusões. Ainda de acordo com Jakubaszko (2015, p. 2), 
Podemos iniciar na sala de aula um processo de desconstrução, talvez, do que Bourdieu chamou de "olhar pré-construído", dos aspectos que a cultura já estabeleceu e definiu para nós e nos é transmitido por meio da linguagem, dos discursos... O reconhecimento e o questionamento dos estereótipos é uma conversão do olhar e é o início do processo de ruptura com o pré-construído.

Assim, é sempre bom esclarecer ao aluno que, segundo Reinaldo Matias Fleuri (2006, p. 498), ao citar Oliveira (2002) em seu artigo intitulado Políticas da diferença: para além dos estereótipos na prática educacional,

Estereótipo indica um modelo rígido a partir do qual se interpreta o comportamento de um sujeito social, sem se considerar o seu contexto e a sua intencionalidade. O estereótipo representa uma imagem mental simplificadora de determinadas categorias sociais. Funciona como um padrão de significados utilizado por um grupo na qualificação do outro. Constitui imagens que cumprem o papel de criar ou acentuar a diversidade. O estereótipo resulta, pois, como um instrumento dos grupos, construído para simplificar o processo das relações entre eles e, nessa simplificação, justificar determinadas atitudes e comportamentos pessoais e coletivos.

Ou seja, segundo Espindola (2010, p. 32), estereótipos são a "configuração que o costume natural do mundo social tem de lidar com o aparecimento do diferente". Trata-se daquilo que não conhecemos direito e, por medo, de enfrentar, criamos afirmações "válidas" para evitar a situação.

\section{CONSIDERAÇÕES FINAIS}

Após discorrer sobre como enfrentei o problema do estereótipo em sala de aula, gostaria de registrar aqui que a ideia de organizar e colocar em prática tal exercício com os alunos foi porque, ao compartilhar o meu descontentamento e desconforto com outros professores sobre como eles [os alunos] estavam reagindo em relação ao fato de eu estar presente em sua sala de aula, notei que todos eles passaram por isso em algum momento de sua vida docente.

Assim, ao mostrar para os estudantes que eles precisavam dar uma chance para aqueles que estivessem chegando e que nem tudo é o que parece ser, e ao ver que o "projeto" resultou na compreensão da mensagem principal que eu gostaria de transmitir para eles, me senti satisfeita e aliviada, pois, agora, sabia que eles poderiam pensar melhor antes de, simplesmente, julgar alguém por conhecimentos prévios não fundamentados em fatos.

Creio que tal "projeto" ajudou os alunos a desenvolveram seu pensamento crítico em relação a como nossos julgamentos devem, de fato, serem levados em consideração ou serem expostos em uma determinada ocasião.

\section{REFERÊNCIAS}

BOURDIEU, P. O Poder Simbólico. Rio de Janeiro: DIFEL e Editora Bertrand Brasil,1989.

ESPINDOLA, P. M. Estereótipos na comunicação intercultural: o caso do intercâmbio cultural na PUCRS. 2010. 128 f. Dissertação (Mestrado) - Curso de Comunicação Social, Faculdade de Comunicação Social - FAMECOS, PUC-RS, Porto Alegre, 2010. Cap. 1.

FELDHAUS, M.; MIZIESCKI, M. Desconstruindo estereótipos: arte, educação e experiência estética. Criar Educação. Criciúma, v. 6, no 1, p. 1-17, jul./nov. 2016.

FLEURI, R. M. Politicas da diferença: para além dos estereótipos na prática educacional. Educação e Sociedade. Ed. Recife, v. 27, p. 495-520, mai.-ago./2006.

HAMAUE, P. Recursos Pedagógicos: o tema do estereótipo na sala de aula. Cadernos de pós-graduação em Letras, v.8, jan.-dez./2008.

JAKUBASZKO, D. Quebrando esterétipos e rompendo preconceitos na sala de aula. Revista Espaço 
Acadêmico. Maringá, V. 14, No 168, p. 1-16, mai. 2015.

OLIVEIRA, A.P. Discurso da exclusão na escola. Joaçaba: UNOESC, 2002.

OLIVEIRA, I. A. de A; SILVA, E. A. da. Estigmatizados: de que forma o professor aborda o preconceito no âmbito escolar, [200?]. Disponível em:http://www.simposioestadopoliticas.ufu.br/imagens/anais/pdf/CP03.pdf. Acesso em: 18 jun. 2017.

PEREIRA, M. E. Psicologia social dos estereótipos. São Paulo, SP: EPU, 2002.

SALAT, K. Estereótipos nossos de cada dia. Youtube, 2015. Disponível em: https://www.youtube.com/watch?v=FcK5dQY7FbY. Acesso em: 18 jun 2017.

SOCHA, Kátia. A Exclusão Escolar no Município de Curitibanos. (Dissertação de Mestrado). FAED / UDESC, Florianópolis, 2004.

Recebido em: 04/03/2018

Aprovado em: 05/06/2018 